\title{
PROMOVENDO O ENVOLVIMENTO E A APRENDIZAGEM DE ESTUDANTES NO ENSINO SUPERIOR: UMA EXPERIÊNCIA COM A ESCRITA CIENTÍFICA NA DISCIPLINA DE QUÍMICA INORGÂNICA
}

\author{
Gilson DeFreitas-Silva ${ }^{\mathrm{a}}$, Roberta Guimarães Corrêa ${ }^{\mathrm{a}}$ e Ana Luiza de Quadros ${ }^{\mathrm{a}, *, \bullet}$ \\ a'Departamento de Química, Instituto de Ciências Exatas, Universidade Federal de Minas Gerais, 31.270-901, Belo Horizonte - \\ MG, Brasil
}

Recebido em 28/08/2021; aceito em 16/11/2021; publicado na web em 17/01/2022

\begin{abstract}
PROMOTING STUDENT ENGAGEMENT AND LEARNING IN HIGHER EDUCATION: AN EXPERIENCE WITH SCIENTIFIC WRITING IN THE INORGANIC CHEMISTRY COURSE. The student who has just entered higher education is faced with chemical knowledge that receives a much deeper treatment when compared to high school so that he is not always able to construct meanings for this knowledge. To help in this construction of meanings, we analyzed an experience in which students of an Inorganic Chemistry course were asked to produce a text based on the reading of a scientific divulgation text and to participate in the evaluation process of their colleagues' texts. We observed a good involvement with the activity and the construction of relationships between the topic in question and the contents developed in the discipline, what contributed to improve the performance of the class. We argue that the involvement with creative writing of scientific texts should be encouraged throughout the entire undergraduate course.
\end{abstract}

Keywords: writing; pedagogical link-making; inorganic chemistry.

\section{INTRODUÇÃO}

Repensar os processos formativos tem sido um desafio em grande parte das instituições de Ensino Superior. O avanço tecnológico, a informatização e a democratização dos conhecimentos afetaram, de certa forma, as instituições de ensino e, por consequência, as práticas pedagógicas de cada um dos professores. A educação unicamente "conteudista" se mostra insustentável, ${ }^{1}$ diante da ampliação do acesso à informação e das mudanças sociais provocadas pela revolução tecnológica. Esse contexto de "mudanças" fez/faz com que os papeis de professor e de estudante também sejam repensados. Os processos formativos, como fruto de atividades individuais e coletivas, devem propiciar espaços de discussão, preparando o estudante para ter voz ativa na tomada de decisões e no agir no mundo. ${ }^{2,3}$

Quando se trata de conhecimentos químicos outros desafios se impõem. Entre eles está o fato de os estudantes da Educação Básica, assim como a sociedade em geral, terem ideias limitadas em relação ao que seja Química e produtos químicos. Pesquisas presentes na literatura ${ }^{4,5}$ têm tratado dessa visão e afirmam que geralmente os produtos químicos estão associados ao que é perigoso (para a saúde ou para a natureza) e ao que é artificial. E essa visão se mantém mesmo entre os sujeitos que passaram pela escola. Ressalta-se que a escola não constrói essa visão limitada de Química, mas à medida que não a problematiza, pode estar contribuindo para a sua manutenção.

Ao ingressar no Ensino Superior os estudantes se deparam com conhecimentos químicos bem mais diversificados e detalhados quando comparados aos conhecimentos químicos estudados no Ensino Médio. Na Química Inorgânica, ao se estudar os metais, por exemplo, os complexos derivados dessas espécies químicas são explorados em termos da constituição, estrutura, formação das ligações químicas e reatividade. O estudante recém-ingressado no Ensino Superior tem dificuldade em fazer relação desse conteúdo com conhecimentos que ele já possui ou com fenômenos de seu contexto social.

A disciplina de Química Inorgânica CI, ofertada pelo Departamento de Química da UFMG, desenvolve os conteúdos relativos à teoria dos orbitais moleculares, classificações de ácidos e bases, estrutura,

*e-mail: aquadros@qui.ufmg.br isomeria e ligações químicas em complexos, além de uma breve introdução ao estudo de materiais inorgânicos. Esses conteúdos não se esgotam nessa disciplina, uma vez que costumam ser retomados em disciplinas subsequentes, tais como Química Inorgânica CII e CIII, Química de Materiais, Química Analítica, entre outras. As aulas da graduação são, normalmente, centradas no professor, que usa prioritariamente recursos como a lousa e o giz e o power point, ${ }^{6}$ sem uma participação ativa dos estudantes. No entanto, pesquisas ${ }^{7,8}$ têm mostrado que a aprendizagem é um processo ativo no qual os estudantes interagem com o conteúdo transformando-o e discutindo-o, a fim de fazer conexões com aquilo que eles já conhecem. O ensino centrado no professor nem sempre favorece que o estudante estabeleça conexões dos novos conhecimentos com aquilo que ele já sabe, ou faça relações/conexões entre os conceitos trabalhados e desses com o contexto, principalmente quando o professor não as estabelece. Essa constatação em relação às aulas do Ensino Superior está presente na literatura, ${ }^{9}$ com o alerta de que o modelo de transmissão/recepção de informações com uma visão empirista/positivista da Ciência continua sendo predominante.

Uma possibilidade que emergiu no intuito de propiciar uma maior relação dos complexos metálicos com o contexto e com a profissão do Químico foi envolver os estudantes na produção de um texto didático a partir da leitura de um texto disponível na internet, que pode ser considerado de divulgação científica. Essa proposta levou em conta que os conhecimentos desenvolvidos nas aulas deveriam ser associados às informações primárias contidas nos textos disponibilizados envolvendo uma situação do contexto, sendo esperado que os estudantes percebessem a direta relação dos conceitos presentes nas aulas com as situações descritas nos textos.

A intervenção foi realizada em uma turma da disciplina de Química Inorgânica CI, dos cursos de Bacharelado e Licenciatura em Química da Universidade Federal de Minas Gerais. Como estratégia foram usados dois textos curtos que destacavam os metais, um deles relativo ao uso do íon cianeto para extração de ouro nos processos de mineração ${ }^{10}$ e o outro sobre a ingestão de suplementos minerais quelados visando uma melhor absorção dessas espécies químicas, produzido por uma nutricionista. ${ }^{11}$ Com isso era esperado que os estudantes se envolvessem mais com o conteúdo desenvolvido nas 
aulas, principalmente com a complexação de metais, e percebessem a relação desse conteúdo com situações do cotidiano e com o campo de trabalho futuro. Essa intervenção também teve a intenção de propiciar um ambiente de ensino no qual o estudante tivesse uma participação mais ativa. Desenvolvemos este trabalho com o objetivo de analisar as potencialidades de uma atividade que envolveu os estudantes de Química Inorgânica na produção de um texto na forma de material didático a partir da leitura de textos selecionados pelo professor e disponíveis na rede mundial de computadores.

\section{O olhar para a literatura}

Scott, Mortimer e Ametller ${ }^{12}$ usam o termo "relação pedagógica" para tratar das formas pelas quais os professores e os estudantes relacionam ideias na sala de aula objetivando a construção de significados. Segundo eles, essas relações são fundamentais para o ensino e a aprendizagem das Ciências, uma vez que o entendimento de um conceito envolve a formação de relações entre o conhecimento existente e as novas ideias que são tratadas nas aulas. Esses argumentos têm origem em pressupostos construtivistas, principalmente nos estudos de Vigotski. ${ }^{13}$ É de Vigotski a ideia de que a aprendizagem acontece primeiro no plano social - pela discussão de ideias - e depois no plano individual, quando o sujeito internaliza uma nova ideia. Nessa perspectiva, relacionar um conceito novo a algo que o estudante já conhece é essencial para que esse conceito faça sentido para ele e, assim, seja internalizado.

Ao desenvolverem estudos envolvendo as relações pedagógicas, Scott, Mortimer e Ametller ${ }^{12}$ dividiram-nas em três grupos principais. No primeiro grupo estão as relações para apoiar a construção do conhecimento, que envolvem conexões: entre explicação científica e explicação cotidiana; entre Ciência e fenômenos; entre os diferentes conceitos; entre os diferentes níveis/escalas de explicação; entre os diferentes modos de representação; e as analogias. No segundo grupo estão as relações de continuidade, que envolvem fazer relações entre conteúdo/conceitos que estão sendo trabalhados naquele momento com conteúdo/conceitos que já foram trabalhados em outros momentos. No terceiro grupo estão as relações cujo objetivo é encorajar o envolvimento emocional do estudante. Ainda que não possamos mensurar os sentimentos dos estudantes, ${ }^{14}$ é possível observar como eles reagem emocionalmente diante do conteúdo/ colegas/professores, lembrando que essas reações podem ser oriundas daquilo que estão sentindo em relação à Ciência que está sendo trabalhada em sala de aula. Já é consensual a ideia de que as crenças que os estudantes trazem para a sala de aula interferem na aprendizagem. E não apenas essas crenças, mas também os valores e a motivação, formam as atitudes/comportamentos dos estudantes em relação à Ciência. ${ }^{15}$ Dessa forma, há muitas maneiras de um professor suscitar uma resposta emocional positiva do estudante $\mathrm{e}$ os dois primeiros grupos de relações pedagógicas podem ser bons aliados no engajamento com o conteúdo das aulas. ${ }^{12}$

No caso de componentes curriculares que tratam de conteúdos com alto nível de detalhamento, como é o caso dos complexos presentes na Química Inorgânica, é indicado que as relações pedagógicas sejam fomentadas para que o estudante possa se apropriar dos conceitos e usá-los para entender tanto os conteúdos subsequentes quanto as situações do contexto. Levando em conta que promover o envolvimento emocional positivo dos estudantes demanda torná-los coprotagonistas nas aulas, fazer com que eles tenham que problematizar uma situação do contexto e inserir conceitos científicos que viabilizem o entendimento dessa situação pode promover tanto o envolvimento emocional quanto o intelectual.

Considerando que devam ser estabelecidas relações tanto entre os conceitos científicos trabalhados em determinada disciplina escolar quanto desses conceitos com o contexto, com outras áreas do saber e com a tecnologia, ressaltamos que alfabetizar cientificamente um estudante implica reconhecer os principais conceitos e princípios da Ciência e se familiarizar com eles. Os complexos estudados na Química Inorgânica e as teorias usadas para a descrição da formação de ligações químicas em complexos, por exemplo, não são nada triviais, nem mesmo para estudantes de graduação. Para fomentar a relação desses complexos metálicos com o contexto, a escrita recebeu atenção e passou a ser mais encorajada como uma atividade educacional que auxilia na estruturação de novos conhecimentos e, portanto, na aprendizagem. ${ }^{16,17}$ Chatel $^{18}$ defende veementemente a escrita na escola, afirmando que o ato de escrever aprofunda a compreensão do conteúdo, reforçando o domínio dos conceitos científicos, além de contribuir para o desenvolvimento de outras habilidades de comunicação, tais como ler, falar, ouvir.

Diversas pesquisas ${ }^{19}$ têm alertado para a pouca atenção que tem sido dada à escrita, apesar das evidências substanciais de que ela pode ser uma ferramenta eficaz para promover a aprendizagem e o envolvimento dos alunos. No entanto, não se trata de qualquer escrita, tipo palavras que saem da lousa e vão para o caderno do estudante, sem passar pela mente. Trata-se de uma escrita que promova a aprendizagem. Escrever para aprender exige que os estudantes relembrem do conteúdo, esclareçam pontos dúbios, questionem tanto o que sabem de um assunto quanto o que ainda se perguntam em relação a esse assunto. ${ }^{20}$ Essa escrita - para aprender - envolve também aumentar a consciência sobre o seu próprio saber em relação a um assunto. Sobre isso, Knipper e Duggan ${ }^{20}$ (p. 462-463) afirmam que "ser capaz de expressar o pensamento por escrito é uma habilidade que os alunos levam para além dos estudos sociais elementares e das aulas de Ciências".

Pelger e Nilsson ${ }^{21}$ investigaram o efeito da escrita de estudantes de graduação envolvidos em projetos de divulgação científica, considerando o ponto de vista dos próprios estudantes. Eles argumentam que no Ensino Superior de Ciências Naturais o relatório científico é o gênero de escrita predominante. Como resultado da investigação realizada por eles, a grande maioria dos estudantes expressou que a escrita de textos de divulgação científica propiciou uma mudança de perspectiva em relação ao assunto objeto dessa escrita, melhorando a compreensão.

Wenzel e Maldaner ${ }^{22}$ defendem o envolvimento do estudante com a escrita e a reescrita nas aulas de Química pelo fato de que a escrita exige um grau de abstração maior quando comparado com a fala. Segundo eles, a escrita auxilia na estruturação do pensamento, ao exigir uma maior organização cognitiva e uma combinação articulada e bem estruturada de palavras, em um processo criativo. Outros trabalhos têm enfatizado a escrita de graduandos participantes de um curso de extensão ${ }^{23}$ e em investigações que visam entender o papel da escrita na graduação do ponto de vista de professores do Ensino Superior. ${ }^{24}$

Reconhecemos o importante papel da escrita no envolvimento dos estudantes com um determinado assunto e na produção de aprendizagens. A escrita, em disciplinas clássicas da graduação em Química, acontece geralmente de forma mais técnica, como é o caso dos relatórios científicos. Valemo-nos do termo "escrita criativa" muito usado no contexto da poesia e da narrativa ficcional ${ }^{25}$ - apenas com a intenção de diferenciar essa construção textual proposta aos estudantes da escrita técnica.

Este trabalho envolveu uma atividade de escrita de um texto, desenvolvida por estudantes em uma disciplina de Química Inorgânica, relacionando o conteúdo da disciplina com uma situação tratada em dois textos selecionados pelo professor, disponíveis na internet. Por ser uma experiência desenvolvida em uma disciplina de Química Inorgânica, descrevemos brevemente alguns trabalhos 
presentes na literatura que acreditamos sejam representativos de pesquisas relacionadas ao ensino dessa disciplina na graduação.

\section{O ensino de Química Inorgânica como foco de pesquisa}

A Química Inorgânica foi destacada em dois trabalhos ${ }^{26,27}$ que fazem uma leitura da área de Química Inorgânica no Brasil, principalmente em termos de pesquisas e de pesquisadores. Levando em conta o que é ensinado nas instituições de Ensino Superior, Toma, Ferreira e Serra ${ }^{26}$ comparam a Química Inorgânica descritiva proposta por Ohlweiler, em 1971, com a Química baseada em teoria de grupos e campo ligante, e ressaltam as críticas que ambas receberam. Eles afirmam que houve uma convergência para o esquema de ensino desenvolvido atualmente em salas de aula no qual estão presentes os aspectos conceituais (estrutura, ligação, termodinâmica), característicos da Química mais descritiva, e que essa Química descritiva está associada à compreensão das propriedades, dos mecanismos, da catálise e da Química organometálica, característicos da Química baseada em teoria de grupos e campo ligante.

Embora essa convergência seja considerada positiva, o Ensino Superior, de maneira geral, vem recebendo críticas de educadores ${ }^{9,28}$ em função da ênfase na transmissão de informações em detrimento do entendimento de como o estudante significa essas informações. Além disso, estudos têm mostrado que os egressos, ao assumirem a docência, acabam por se apropriar dos mesmos métodos de ensino de seus professores universitários. ${ }^{29} \mathrm{E}$ isso não é diferente no campo da Química Inorgânica, cujas disciplinas também são organizadas com um vasto conteúdo programático, no qual é comum o professor, para dar conta de todo o programa, optar pela ênfase no conteúdo e não no seu processo de significação. Destacamos a seguir algumas pesquisas nacionais envolvendo o ensino e a aprendizagem de Química Inorgânica.

Gomes, Mendes e Calefi ${ }^{30}$ realizaram uma intervenção em uma disciplina de Química Inorgânica I do curso de Licenciatura em Química da UFES utilizando a Aprendizagem Baseada em Problemas (ABP). Segundo os autores, os 14 estudantes participantes tiveram dificuldades em se adaptar à metodologia proposta, uma vez que não estavam acostumados a trabalhar de forma autônoma. No entanto, foram capazes de apresentar soluções criativas para os problemas propostos $\mathrm{e}$, para isso, fizeram uso de recursos relacionados à profissão futura, o que levou os autores a defenderem a inserção da ABP. Essa abordagem (ABP) também foi usada em uma disciplina experimental de Química Inorgânica, ${ }^{31}$ com ênfase para o desenvolvimento da escrita dos estudantes, quando da organização dos projetos.

Leite e Leite, ${ }^{32}$ considerando que estudantes do curso de Engenharia Química da UFRJ apresentavam pouco interesse com conteúdos de Química Inorgânica, pouca autonomia para estudar e, como consequência, rendimento insuficiente, propuseram uma intervenção que trouxesse melhorias nesse quadro. Para tanto, eles introduziram um ambiente virtual de aprendizagem (b-learning) que visava fomentar a colaboração entre os pares e a autoaprendizagem. Com isso, os proponentes ressignificaram o papel do professor, passando de único responsável pela relação ensino-aprendizagem para guia/mentor/incentivador de seus estudantes. Segundo os autores, o uso desse ambiente virtual com enfoque na aprendizagem colaborativa fez com que a participação dos estudantes aumentasse significativamente e, como consequência, o desempenho, em termos de nota e aprovação, ficasse acima da média dos anos anteriores.

Simões Neto, Campos e Marcelino-Jr., ${ }^{33}$ buscando apresentar alternativas ao uso de lousa/giz e de slides/power point e outros marcadores de texto, comuns nas aulas do Ensino Superior, utilizaram-se de duas situações-problema envolvendo a isomeria, em aulas de Química Inorgânica. De acordo com os autores, com a experiência foi possível contribuir tanto para a formação conceitual quanto para modificar um pouco a visão tradicional predominante nas salas de aula do Ensino Superior.

A Química Inorgânica também foi explorada em conjunto com a Química Geral. ${ }^{34}$ Ao problematizarem o tópico "funções inorgânicas" e as definições de ácido e base presentes em livros didáticos de Ensino Superior, esses autores ${ }^{34}$ apontam para um acúmulo de classificações que acabam por confundir as definições, o que gera distorções no aprendizado, uma vez que os conceitos de acidez e basicidade são relativos à reatividade e não à composição. Por meio de um questionário eles identificaram que os estudantes confundem os termos e argumentam que essa confusão decorre dos obstáculos epistemológicos presentes nos livros e no próprio ensino, e para tanto, eles defendem a necessidade de se discutir mais amplamente os aspectos epistemológicos desse conteúdo.

A sessão de Educação do periódico Química Nova traz relatos de pesquisa envolvendo o ensino de algum tópico específico de Química Inorgânica. Entre eles estão experiências envolvendo a química de coordenação, ${ }^{35}$ a teoria de grupos, ${ }^{36}$ as biomoléculas de metais de transição ou metalobiomoléculas, ${ }^{37}$ as configurações eletrônicas de elementos de transição, ${ }^{38}$ a teoria do campo cristalino ${ }^{39} \mathrm{e}$ a teoria do orbital molecular para moléculas poliatômicas simples. ${ }^{40}$ Porém, nesses casos, a ênfase está no conteúdo ministrado pelo professor.

\section{METODOLOGIA}

Para que o estudante pudesse perceber a direta relação do conteúdo de complexação de metais com situações do contexto, o professor da turma na qual se deu a atividade aqui relatada selecionou dois textos, ${ }^{10,11}$ por serem curtos e usarem uma linguagem menos paradigmática. Os textos escolhidos como ponto de partida no desenvolvimento do trabalho tratavam de bioacumulação de metais e de mineração. Esses temas poderiam facilmente ser relacionados ao conteúdo da disciplina porque envolvem, em muitas situações, a formação de complexos metálicos e a química dessas espécies.

No caso da mineração do ouro, o processo hidrometalúrgico de cianetação envolve a complexação do ouro com íon cianeto para promover a extração desse metal, conforme sintetizado na equação a seguir. No texto selecionado foi dado destaque para os impactos ambientais e na saúde humana decorrentes do íon cianeto, o que também poderia levar os estudantes a buscarem uma substituição para esse íon.

$$
\begin{aligned}
& 2 \mathrm{Au}(\mathrm{s})+4 \mathrm{CN}^{-}(\mathrm{aq})+1 / 2 \mathrm{O}_{2}(\mathrm{~g})+2 \mathrm{H}^{+}(\mathrm{aq}) \rightarrow 2\left[\mathrm{Au}(\mathrm{CN})_{2}\right]^{-}(\mathrm{aq})+ \\
& \mathrm{H}_{2} \mathrm{O}
\end{aligned}
$$

Em relação à bioacumulação de espécies metálicas, a maior parte das interações pode ser entendida com base no conceito de Pearson para ácidos e bases. O mercúrio, por exemplo, é considerado um ácido macio (segundo a classificação de Pearson) e tende a formar complexos mais estáveis com bases que tenham átomos doadores de caráter macio, como é o caso de espécies com o átomo de enxofre. A partir dessa premissa é possível entender a interação preferencial de centros metálicos com determinadas moléculas do organismo. No texto selecionado pelo professor havia menção às interações entre os nutrientes e ao quanto um nutriente pode interferir na biodisponibilidade de outro. Nesse sentido, a complexação dos metais pode ser uma alternativa viável para reduzir essa interferência, embora os metais quelados nem sempre sejam eficientes em termos de liberação de metais no organismo. ${ }^{41}$

A tarefa principal dos estudantes, no entanto, envolveu a escrita. Inúmeras pesquisas têm sido desenvolvidas ${ }^{16,18.22,42}$ visando analisar o papel da escrita na aprendizagem, por meio de diversos modelos didáticos. Essas investigações argumentam que a escrita não tem 
um papel puramente comunicativo, mas pode representar um aprendizado adicional para os estudantes desde que seja oferecida a eles a oportunidade de "desempacotar" informações de forma a construir significados e, assim, reconstruir entendimentos. Para que isso aconteça, McDermott e Hand ${ }^{43}$ defendem que os estudantes devem ser solicitados a combinar várias maneiras de representar uma informação conceitual da Ciência usando diagramas, tabelas, gráficos, equações, entre outros recursos, combinados com os textos.

Assim, os 28 estudantes participantes da disciplina de Química Inorgânica se dividiram em oito grupos, ficando quatro grupos com um tema e quatro com o outro. $\mathrm{O}$ tema de cada grupo foi definido por sorteio realizado pelos próprios estudantes. Eles foram informados que deveriam, a partir do texto disponibilizado pelo professor, buscar mais informações sobre o assunto e, como produto, entregar um texto didático que pudesse fazer parte de um livro didático (fictício) de Química Inorgânica, na forma de seção complementar, denominada "Para Saber Mais". Para facilitar o entendimento em torno de que tipo de texto deveria ser construído, um livro de Química Inorgânica ${ }^{44}$ foi disponibilizado aos estudantes, destacando algumas sessões presentes nesse livro (Quadro 4.1, p. 151; Quadro 4.2, p. 157; Quadro 8.1, p. 255; Quadro 8.2, p. 256), que continham uma estrutura semelhante ao texto que os estudantes deveriam produzir. O professor indicou, ainda, que a leitura deveria ser "agradável" e, para isso, poderiam usar imagens, fotografias etc. Após a entrega ao professor, os textos produzidos foram avaliados pelos pares, em um processo no qual os estudantes avaliam e são, também, avaliados. ${ }^{45}$ Essa avaliação, de acordo com as orientações do professor, deveria considerar a clareza e objetividade do texto, a coerência na sequência de ideias, a relação com a temática "complexos" e a coerência científica. Para cada um desses itens os estudantes poderiam destinar o máximo de 5 pontos, justificando cada nota, e a totalização seria a média dessas quatro notas. Essa avaliação foi feita por escrito e entregue ao professor. Cada grupo avaliou o texto de um outro grupo, sendo essa distribuição feita por sorteio, no momento da distribuição da textos.

Essa tarefa foi entregue aos estudantes na quarta semana da disciplina, entre o término do estudo da teoria do orbital molecular aplicada a moléculas poliatômicas e o início do estudo dos complexos metálicos. A entrega do texto escrito foi marcada para sete semanas depois, quando todo o conteúdo de complexos já tivesse sido desenvolvido e a avaliação na forma de prova já tivesse acontecido.

Nossa análise dos textos produzidos se deu, em um primeiro momento, no sentido de identificar o envolvimento dos estudantes e, para isso, a opinião e os dados trazidos pelo professor da disciplina foram fundamentais. Em relação aos trabalhos escritos, eles foram lidos de forma independente por cada um dos pesquisadores, marcando nesses textos o uso de modos semióticos variados, a capacidade de relacionar o tema com o conteúdo da disciplina e a qualidade do texto como um todo. Após, as diferentes análises foram reunidas e discutidas, com a intenção de consolidar essa análise. Com a avaliação feita pelo professor e pelos estudantes (pares), olhamos inicialmente para os pontos destacados pelos grupos em relação aos trabalhos analisados por eles e, após, comparamos a avaliação dos estudantes com a avaliação feita pelo professor.

\section{RESULTADOS E DISCUSSÃO}

\section{Envolvimento com a atividade}

A atividade foi iniciada com a leitura dos textos entregues aos estudantes e, já nesse momento, surgiram algumas dúvidas em relação ao que deveria ser explorado no trabalho. O professor informou, então, que o conteúdo desenvolvido nas aulas deveria ser considerado, o que envolvia a estrutura dos complexos e os modelos de ligações químicas (TLV, TCC e/ou TOM), a isomeria, a nomenclatura, entre outras possibilidades de conteúdo. Em relação ao tema, o professor foi questionado pelos estudantes se, no caso da mineração, deveriam considerar apenas a obtenção do ouro. Apesar de o professor ter autorizado que outros minerais pudessem ser tratados, os quatro grupos acabaram por considerar apenas o ouro, provavelmente por haver uma ampla fonte de informações na rede mundial de computadores.

Ao longo do período destinado à realização do trabalho, três grupos procuraram o professor em horário extraclasse para discutir brevemente o que queriam fazer. Segundo o professor, esses três grupos foram os que apresentaram trabalhos mais completos e aprofundados. Os demais grupos ou informaram de forma sucinta o que estavam fazendo, quando foram perguntados em sala de aula, ou deixaram a organização para as semanas imediatamente anteriores à data de entrega.

Percebemos que o fato de não haver uma delimitação mais específica do tema fez com que os estudantes usassem uma parte significativa do tempo para definir o subtema a ser explorado dentro do tema mais amplo (mineração do ouro e bioacumulação). Consideramos que essa foi uma limitação da atividade, uma vez que o texto a ser produzido como parte de um livro didático deveria fazer uma relação direta com o conteúdo científico e, para isso, o subtema poderia ter sido indicado previamente.

Nas duas semanas anteriores à entrega do trabalho, o envolvimento dos estudantes foi bem mais intenso, pois usaram momentos prévios e posteriores às aulas para falar de dificuldades em obter materiais adequados que fossem de fontes confiáveis e também de curiosidades que encontraram mesmo que elas não fossem usadas no trabalho, entre outros comentários. Vale ressaltar que o fato de estarem no primeiro ano do curso pode ter contribuído para a pouca familiaridade com as ferramentas de busca. O momento da avaliação, no entanto, parece ter sido o mais intenso, já que os estudantes se mostraram empolgados com a atividade e usaram mais de uma hora-aula para realizar essa atividade.

\section{A produção dos estudantes}

Os estudantes receberam a orientação de que o texto deveria ser produzido para ser usado em um livro didático fictício, na forma de caixa de texto que poderia ser identificada como "Para saber mais". Considerando que as quatro sessões do livro levado pelo professor, que serviu como base para a produção do texto escrito, traziam equações químicas e/ou desenhos de estruturas químicas o professor sugeriu que poderiam ser usadas imagens. Assim, nosso primeiro olhar foi para os modos semióticos usados na produção do texto. Como a linguagem é multimodal por natureza, ${ }^{46,47}$ um texto escrito tende a ser, também, multimodal. No caso de um livro didático, mesmo aqueles que aparentam ser exclusivamente verbais possuem características visuais tais como margens, cores e leiaute que os configuram como multimodais. ${ }^{48}$

Textos aparentemente uni/monomodais, que priorizavam a linguagem verbal, perderam espaço nos livros didáticos nas últimas décadas. Os inúmeros softwares de composição multimídia facilitaram a criação de imagens, que passaram a ser inseridas nos textos escritos, como é o caso do livro didático. O texto multimodal, portanto, reúne vários modos semióticos - imagens, gráficos, diagramas, equações químicas, equações matemáticas, entre outros modos - para auxiliar no entendimento do que está sendo transmitido. No entanto, esses modos devem atuar de forma integrada, para auxiliar o leitor na construção de significados para aquilo que o texto intenciona ensinar. Eles representam uma forma precursora de hipertexto, cuja leitura pode 
ter múltiplos caminhos, desde que esses diferentes modos estejam conectados entre si.

Para essa análise partimos da premissa de que os multimodos são constituintes de um texto didático. Apesar de esses estudantes terem pouca experiência com a escrita de textos científicos, já tinham tido contato com uma grande variedade de livros didáticos, principalmente na Educação Básica, e poderiam ter percebido que a inserção de imagens, figuras e outros modos pode contribuir para tornar a leitura mais agradável, mesmo no caso de um texto curto.

Ao analisar os textos produzidos pelos estudantes, notamos que dois grupos (1 e 4), que trataram da bioacumulação, produziram textos contendo apenas a escrita. Além disso, exploraram pouco os recursos da escrita, tais como o negrito, caixa alta ou outros recursos que poderiam destacar partes do texto. As fórmulas moleculares dos compostos citados nesses dois textos apareceram integradas à escrita. Listamos no Quadro 1 os modos, além da escrita, presentes nos textos dos demais grupos, informando entre parênteses o número de vezes em que foram usados:

Quadro 1. Modos semióticos usados pelos estudantes para a construção dos textos

\begin{tabular}{|l|l|}
\hline Grupos & Modos semióticos presentes no texto \\
\hline 2 & Estrutura química (1); equação química (2) \\
\hline 3 & Estrutura química (4); equação matemática (2) \\
\hline 5 & $\begin{array}{l}\text { Estrutura química (1); equação química (2); diagrama (2); } \\
\text { imagem (1) }\end{array}$ \\
\hline 6 & $\begin{array}{l}\text { Estrutura química (1); equação química (1); diagrama (1); } \\
\text { imagem (1); tabela (1) }\end{array}$ \\
\hline 7 & Diagrama (1); imagem (1); tabela (1) \\
\hline 8 & $\begin{array}{l}\text { Equação química (3); diagrama (2); equação matemática (1); } \\
\text { tabela (1) }\end{array}$ \\
\hline
\end{tabular}

Fonte: autores.

Apesar de ser solicitado um texto curto, de duas ou três páginas (que em um livro se tornariam uma página), observamos que os estudantes - com exceção de dois grupos - se utilizaram de outros modos para representar uma informação científica. O uso de modos variados, que em um primeiro momento tende a dar a sensação de que a leitura será mais fluida e menos cansativa, pode ser uma evidência do esforço desses estudantes em entender melhor as informações e em organizá-las. No entanto, é necessário um olhar para como esses modos se integram ao texto escrito.

Prain e Hand ${ }^{49}$ argumentam que os significados que os estudantes atribuem à própria escrita dependem do entendimento que possuem dos outros modos semióticos usados e da capacidade deles em integrar esses modos e seus significados com a escrita. Sobre isso os autores afirmam:

ao aprender sobre qualquer tópico de Ciências, os estudantes precisam necessariamente compreender a forma/função de diferentes modos semióticos e serem capazes de integrar/ incorporar esses modos de forma coerente para que as afirmações que fazem sejam convincentes. ${ }^{49}$ (p. 5)

Observamos nos textos produzidos pelos grupos 5 e 7 uma conexão muito limitada entre os diferentes modos semióticos. $\mathrm{O}$ Grupo 5, por exemplo, conectou as duas equações químicas com o texto escrito por meio de uma indicação, direcionando o olhar do leitor para essas equações, o que tornou esse modo complementar às informações escritas. Porém, no caso dos diagramas, da imagem e da estrutura química, elas parecem "soltas" no texto, sem que haja qualquer referência a elas durante a escrita. Acreditamos que a relação entre os diversos modos em um texto escrito deva receber mais atenção durante o curso de graduação.

Os demais grupos (2, 3, 6 e 8$)$ construíram um texto mais coerente em termos de modos semióticos. O Grupo 8, por exemplo, ao tratar da formação do complexo dicianetoaurato(I), $\left[\mathrm{Au}(\mathrm{CN})_{2}\right]^{-}$, apresentou uma equação química que representa a extração do ouro usando o cianeto. Em seguida, fazendo referência à equação, eles explicaram o processo de cianetação. Logo após foram apresentados e discutidos dois diagramas referentes à descrição da formação da ligação química nessa espécie (Teoria de Ligação de Valência - TLV e Teoria de Campo Cristalino - TCC). Depois disso foi apresentada uma tabela com as constantes de formação de alguns íons, entre eles o $\left[\mathrm{Au}(\mathrm{CN})_{2}\right]^{-}$, para mostrar que esse complexo possui a maior constante, o que favorece a espontaneidade para a formação dessa espécie química e, portanto, faz com que seja o mais usado.

O texto produzido pelo grupo 8 , assim como aconteceu com os outros três grupos (2, 3 e 6), combinou várias maneiras de representar uma informação científica. Nesses casos, baseados nos estudos de McDermott e Hand, ${ }^{43}$ argumentamos que a escrita se mostrou como um processo de construção de significados e de reconstrução de entendimentos.

Um segundo olhar para essa produção foi no sentido de analisar a capacidade de relacionar o tema - mineração ou bioacumulação - aos conceitos científicos desenvolvidos ao longo da disciplina, principalmente as teorias usadas para a descrição da formação da ligação química em complexos (TLV, TCC e Teoria de Orbital Molecular - TOM). Observamos que o estabelecimento dessas relações variou significativamente em função do tema usado pelos grupos. Dos quatro grupos que trataram da bioacumulação, apenas o Grupo 1 usou as teorias, mas sem apresentar os diagramas. Os demais sequer citaram essas teorias. Já os grupos que trataram da mineração, mais especificamente a extração de ouro, de alguma forma fizeram uso dessas teorias, sendo que o Grupo 5 explorou a TLV e TOM, os grupos 6 e 7 exploraram a TCC e o Grupo 8 explorou a TLV e a TCC.

$\mathrm{O}$ fato de ter sido menor a associação do tema bioacumulação com as teorias de ligação pode estar relacionado com o pouco desenvolvimento desse tema em termos químicos, na literatura. Geralmente, essa descrição ocorre em livros de Química Bioinorgânica, fontes que observamos que não foram buscadas pelos estudantes, o que acreditamos decorrer do fato de estarem no primeiro ano do curso superior, não lhes sendo familiar realizar buscas em diferentes fontes. Por outro lado, o tema extração do ouro é mais amplamente explorado e vários textos estão disponíveis na internet, geralmente "carregados" de termos químicos que se tornaram familiares aos estudantes (equações químicas representando a formação dos complexos, constantes de formação etc.). Possivelmente isso favoreceu que os quatro grupos que usaram o tema extração de ouro fizessem a associação entre a formação do complexo de ouro com as diferentes teorias de ligação aplicadas a esse complexo.

Em um terceiro olhar, procuramos analisar a qualidade do texto como um todo. Por se tratar de estudantes de início de curso, tínhamos ciência de algumas possíveis limitações e de que o envolvimento com a produção de um texto didático poderia auxiliá-los também em termos de aprendizagem relativa à redação. Observamos que, em alguns casos, foram usados conceitos científicos cujos significados não são compartilhados na esfera pública da sala de aula, na maioria das vezes sem que fossem explicitados esses significados. Por exemplo, no texto produzido pelo Grupo 4, que tratou mais de situações do contexto em detrimento da Ciência presente nessas situações, foi citada a "biomagnificação" sem que houvesse qualquer explicação para esse processo. A biomagnificação ocorre quando há acúmulo progressivo de substâncias de um nível trófico para outro ao 
longo da teia alimentar ${ }^{50}$ enquanto a bioacumulação, tema do grupo 4 , pode ocorrer de forma direta, quando as substâncias são assimiladas a partir do meio ambiente (solo, sedimento, água) ou de forma indireta pela ingestão de alimentos que contêm essas substâncias. Esses dois processos - bioacumulação e biomagnificação - podem ocorrer de forma simultânea. No texto em questão (Grupo 4), o significado de biomagnificação não foi explicado.

Outro indício de limitação dos estudantes está relacionado ao uso de textos de referência. Durante as aulas os estudantes já haviam comentado a dificuldade em encontrar referências confiáveis na internet e, ao que parece, as orientações recebidas do professor foram suficientes para que eles buscassem publicações validadas pela comunidade científica. Contudo, notamos que algumas fontes citadas no texto não estavam na lista final de referências, embora o mais comum tenha sido uma lista de referências que não foram citadas ao longo do texto. Também foram percebidos uns poucos erros conceituais, alguns deles oriundos de fontes secundárias, mesmo os estudantes tendo citado a fonte primária. Como exemplo, mencionamos um complexo de fórmula " $\left[\mathrm{Au}(\mathrm{Tu})_{2}\right]^{+}$", em uma tabela de constantes de estabilidade usada pelos grupos 6 e 7. A fonte citada pelos estudantes ${ }^{51}$ não continha a tabela e não trazia a referida fórmula. Em pesquisa na internet encontramos a tabela utilizada pelos estudantes em um capítulo de livro, ${ }^{52}$ tendo como referência a mesma fonte primária citada no texto dos estudantes (Figura 1). Esse certamente é um forte indício de pouca atenção à conferência de fontes primárias, o que leva à multiplicação de uma informação equivocada. Equívocos desse tipo precisam ser discutidos com os estudantes de graduação, pois nossa experiência como professores formadores tem mostrado que ele acontece até mesmo nos trabalhos de final de curso.

\section{Tabela 1}

Constantes de Estabilidade dos Complexos de Au(I) (Nicol et alii, 1987)

\begin{tabular}{ll}
\hline Complexo & $\log B^{\prime}$ \\
\hline $\mathrm{Au}(\mathrm{CN})_{2}{ }^{+}$ & 38 \\
$\mathrm{Au}(\mathrm{Tu})_{2}{ }^{+}$ & 23,3 \\
$\mathrm{Au}\left(\mathrm{S}_{2} \mathrm{O}_{3}\right)_{2}{ }^{3 \cdot}$ & 28,7 \\
$\mathrm{Au}(\mathrm{SCN})_{2}{ }^{\cdot}$ & 17,1 \\
$\mathrm{AuBr}{ }_{2}{ }^{-}$ & 12 \\
$\mathrm{Au} \mathrm{Cl}{ }^{*}$ & 9 \\
\hline
\end{tabular}

$1_{B}$ representa a constante de equiibrio para a seguinte reação de complexação do metal: $\mathrm{Au}^{+}+\mathrm{nC}^{-m}=\mathrm{Au}(\mathrm{C})_{\mathrm{n}}{ }^{1-\mathrm{m}}$; Tu representa tiouréia, $\mathrm{CS}\left(\mathrm{NH}_{2}\right)_{2}$.

Figura 1. Tabela usada nos textos dos grupos 6 e 7. Fonte: ref. 52

Essas imprecisões apresentadas nos textos vêm reforçar a necessidade de inserir os estudantes nas práticas de escrita de textos acadêmicos - artigos científicos, ensaios, resenhas acadêmicas, projetos de pesquisa, entre outros - para que eles aprimorem sua escrita ao longo de sua formação acadêmica. Na literatura, ${ }^{53}$ há alertas de que o estudante precisa ser estimulado na produção de trabalhos acadêmicos que propiciem tanto o desenvolvimento de um conjunto de competências de escrita quanto de compreensão da realidade prática, relacionando a escrita com a teoria apreendida em sala de aula. Também há alertas ${ }^{54}$ para o fato de que parte dos professores universitários não considera essa pouca familiaridade dos estudantes com a escrita acadêmica e, assim, não costuma "ensinar" suas especificidades. O problema com o uso de fontes secundárias, como foi o caso da tabela presente na Figura 1, pode ser usado tanto para "ensinar" essa especificidade da escrita como para tratar dos preceitos éticos.

\section{A avaliação por pares}

Logo no início da aula os estudantes se mostraram ansiosos e empolgados com a tarefa, talvez pela curiosidade em saber o que os outros grupos haviam feito ou pela responsabilidade em fazer essa atividade, já que a nota dada por eles aos trabalhos dos colegas seria usada para compor a nota total do trabalho. Como já dissemos, a distribuição foi novamente feita por sorteio, como sugestão dos próprios estudantes, mantendo a reciprocidade (se o Grupo 1 avalia Grupo 6, o Grupo 6 avalia Grupo 1).

Após lerem o trabalho do grupo que estavam avaliando os estudantes usaram um tempo maior do que era esperado pelo professor para fazer essa avaliação, ultrapassando o tempo de uma hora-aula. Nessa avaliação, que foi entregue por escrito, observamos que eles se mostraram bastante críticos, talvez até mesmo seguindo uma tendência do que veem acontecer na universidade em termos de avaliação. Os grupos apontaram problemas organizacionais e conceituais, como pode ser percebido no comentário que segue:

A redação está ruim e em alguns momentos incompreensível, por conter graves erros. $O$ texto se apresenta em blocos de ideias que não se comunicam. [...] Por outro lado, no que tange ao conteúdo de complexos, o texto é claro e, inclusive, apresenta os diagramas de TLV, TOM e a modelagem do complexo. Esses diagramas poderiam ser mais discutidos, para não parecerem "largados" no texto. (Grupo 4 avaliando o Grupo 5)

Ao mesmo tempo que o Grupo 4 apontou problemas no texto, também foi ressaltado o uso das teorias trabalhadas em aula, demonstrando uma percepção tanto do objetivo do trabalho quanto do desempenho do grupo 5 nessa produção. Observamos que, embora não tenham usado as teorias que descrevem a formação da ligação química em complexos, ao tratarem do tema de bioacumulação, os estudantes do Grupo 4 destacaram a presença dessas teorias no trabalho por eles avaliados, o que mostra certa contradição. Porém, em termos de redação, o texto do Grupo 4 apresentou uma linguagem formal, própria de um texto científico, praticamente sem qualquer erro ortográfico/gramatical. Nesse aspecto, a crítica feita ao Grupo 5 não apresenta contradição com sua própria produção.

Essa percepção de pouca ligação do tema com o conteúdo das aulas no trabalho do grupo avaliado foi mais perceptível nas avaliações pareadas entre os grupos 1 e 6 . Os dois grupos ressaltaram a pouca conexão com o conteúdo das aulas, ou seja, criticaram essa não conexão com o conteúdo. No entanto, nenhum deles havia feito uma conexão forte. Enquanto o Grupo 6 citou apenas a TCC, o Grupo 1 não fez nenhuma referência a essas teorias. Com isso, argumentamos que mesmo que esses estudantes não tenham feito as devidas conexões no próprio trabalho, eles entenderam que elas deviam constar do trabalho avaliado. É possível que o processo de avaliação tenha auxiliado a perceber limitações no próprio trabalho por meio das limitações observadas no trabalho dos colegas, embora isso não tenha sido objeto de investigação, como realizado no trabalho de Peron et al.$^{45}$ Ressaltamos que tivemos acesso à avaliação preliminar do professor da disciplina, feita antes da avaliação entre grupos e não compartilhada com os estudantes. Chamou-nos a atenção que a avaliação feita pelo Grupo 5 destacou, na forma de texto, praticamente os mesmos itens destacados pelo professor em relação ao Grupo 4. No Quadro 2 colocamos parte das duas avaliações: 
Quadro 2. Partes da avaliação do professor e dos estudantes, feita para o texto do Grupo 4

\begin{tabular}{|c|c|}
\hline Itens destacados pelo professor & Parte do texto dos estudantes \\
\hline $\begin{array}{l}\text { Rever ordem de apresentação das } \\
\text { referências - nem todas as listadas } \\
\text { estão no texto. } \\
\text { Não explorou os conteúdos discu- } \\
\text { tidos em aula, relativos aos com- } \\
\text { plexos. } \\
\text { Não explorou aspectos químicos (ex. } \\
\text { biomagnificação). }\end{array}$ & $\begin{array}{l}\text { De modo geral o texto está bem es- } \\
\text { crito, mas as ideias não se conectam } \\
\text { tão bem. [...] faltou explicar alguns } \\
\text { conceitos não triviais. Faltou, tam- } \\
\text { bém, colocar no texto as referências, } \\
\text { em alguns parágrafos. Citaram ape- } \\
\text { nas um complexo ao longo do texto, } \\
\text { mas o assunto "complexo" não foi } \\
\text { explorado no texto. }\end{array}$ \\
\hline
\end{tabular}

A avaliação feita pelo Grupo 5 mostra uma percepção clara do que poderia dar mais consistência a um texto didático e segue a orientação do professor. Ao que nos parece, ao avaliar o trabalho do outro com certo "rigor", os estudantes mostraram domínio do conteúdo abordado nos textos e que, ao longo da disciplina/aulas e da realização desse trabalho houve aprendizagem. Segundo dados fornecidos pelo professor, dos 28 estudantes que cursaram Química Inorgânica I nesse semestre, apenas seis foram reprovados, índice considerado muito abaixo dos semestres anteriores. Não podemos garantir que isso se deve ao envolvimento dos estudantes com esses dois temas e com as atividades relacionadas a eles, mas certamente isso contribuiu para esse resultado.

Em relação ao rigor usado pelos estudantes para avaliar o trabalho dos colegas, o professor relatou que já no início da disciplina ele informa que será exigente em relação à escrita dos estudantes e ao uso da linguagem química. Ele relatou também que, ao entregar qualquer avaliação feita e já corrigida, ele a discute com os estudantes também em relação ao uso da linguagem química e ao sentido do que está escrito nas respostas. Com isso, muitos estudantes conseguem perceber que a ideia presente na resposta não era exatamente aquilo que eles almejavam responder. Essa postura do professor pode ter contribuído para que os estudantes fossem mais rigorosos na avaliação dos pares do que na avaliação de seus próprios trabalhos.

Esse olhar para a avaliação pelos pares permitiu a construção de uma ideia mais consistente em relação ao envolvimento dos estudantes e da possível aprendizagem. $\mathrm{O}$ fato de grupos terem estabelecido pouca relação do texto escrito com o conteúdo trabalhado na disciplina mostra uma limitação dos estudantes. No entanto, ao avaliarem o trabalho de outro grupo e criticarem a pouca relação com o conteúdo da disciplina ou ressaltarem o fato dessa relação ter sido construída são indícios de que perceberam a necessidade de uma relação direta entre texto e conteúdo, mesmo não tendo se dedicado a isso com afinco durante a escrita. Acreditamos que esse momento de avaliação por pares pode ter representado uma oportunidade de entendimento e de conscientização dos estudantes em relação a suas próprias limitações e às dificuldades/facilidades na escrita científica. ${ }^{24}$

\section{CONCLUSÕES}

Com este trabalho tínhamos o objetivo de analisar as potencialidades de uma atividade que envolveu os estudantes de Química Inorgânica na produção de um texto na forma de material didático a partir da leitura de textos disponíveis na rede mundial de computadores. A essa atividade foi adicionado o processo de avaliação por pares. Dessa forma, entendemos que o desfecho dessa atividade estaria diretamente relacionado à autonomia dos estudantes e à capacidade de relacionar o tema com o conteúdo da disciplina.

A busca por informações fez com que parte deles procurassem o professor para receber orientações nesse sentido. Nesse caso, acreditamos que a autonomia estava se desenvolvendo, embora os estudantes estivessem percebendo as próprias limitações. Para outros, foi preciso que o professor alertasse, durante as aulas, para a necessidade de ação. Baseados em outros estudos, ${ }^{18}$ já esperávamos que, embora criativos, esses estudantes não tivessem familiaridade com ações autônomas na escolha de caminhos possíveis para a resolução de um problema. Sabemos, no entanto, que essa familiaridade deve ser construída desde o início do curso.

Observamos que a atividade fomentou as relações pedagógicas de conteúdo, na medida em que os estudantes passaram a buscar informações relativas ao tema (bioacumulação ou extração de ouro) e a perceber que os conteúdos da disciplina eram usados para explicar os processos presentes nos temas, principalmente no caso da extração de ouro por cianetação. Isso, de certa forma, suscitou uma resposta emocional positiva dos estudantes, ${ }^{5}$ que foi percebida na empolgação ao receberem a tarefa de construir um texto a ser inserido em um livro didático fictício, ao assumirem o papel de avaliadores dos textos produzidos pelos seus pares e nos resultados da disciplina como um todo.

Ao perceberem que muitos conceitos discutidos durante as aulas auxiliavam no entendimento dos fenômenos que faziam parte do tema, os estudantes passaram a se envolver mais com as aulas, ou seja, a relação dos conceitos científicos com o tema auxiliou na construção de significados para aquilo que era estudado durante as aulas. Com isso, o desempenho dos estudantes melhorou significativamente, resultando em maior índice de aprovação. Resultado semelhante foi evidenciado em outra pesquisa, ${ }^{19}$ já mencionada.

Destacamos, também, limitações dos estudantes em relação à escrita. Eles foram mais eficientes em identificar falhas nos textos produzidos pelos colegas do que nos seus próprios textos. Além disso, alguns grupos foram econômicos no uso de diferentes modos semióticos, produzindo textos que apresentavam o modo "escrita" acompanhado apenas de alguma equação química ou matemática. Nesses casos, as imagens, gráficos, diagramas e outros modos foram pouco explorados, o que traz implicações para o curso de formação, de inserção da multimodalidade como um aspecto importante na escrita.

Como desafio, propomo-nos a ampliar essa experiência, no sentido de transpor algumas limitações ao longo do trabalho, valendonos principalmente de três estratégias. A primeira delas envolve a definição de subtemas, para que os estudantes sejam mais objetivos em suas buscas. A segunda, leva em conta ensinar os estudantes a usar as ferramentas de busca, o que acreditamos poderia ser feito no momento da proposta do trabalho aos estudantes. A terceira estratégia está relacionada à organização de uma agenda na qual os estudantes possam socializar as informações coletadas para construção do texto, aumentando o compromisso do estudante e a organização do trabalho como um todo. Nesse momento de socialização, aspectos importantes da escrita científica poderiam ser explorados, como é o caso da multimodalidade, da opção por referências primárias, entre outros aspectos.

Ao analisarmos os dados obtidos com essa atividade, argumentamos que é fundamental mostrar aos estudantes a importância de aprender conceitos científicos e com eles entender fenômenos que ocorrem no ambiente ou até mesmo no nosso corpo. Esses estudantes puderam perceber o significado do conteúdo presente na disciplina de Química Inorgânica, enquanto o professor, ao inserir essa atividade, pôde observar um maior envolvimento dos estudantes com as aulas. De certa forma, a atividade criou eventos que foram relevantes para os estudantes, auxiliando-os no desempenho na disciplina.

\section{REFERÊNCIAS}

1. Freire, P.; Pedagogia do oprimido, Paz e Terra: Rio de Janeiro, 2005. 
2. Mühl, E. H.; Habermas e a Educação: ação pedagógica como agir comunicativo, UFP: Passo Fundo, 2003.

3. Zoller, U.; Canadian Journal of Education 1992, 17, 86.

4. Quadros, A. L.; A Química no Formação do Técnico Agrícola: potencialidades inexploradas, Ed. UNIJUÍ: Ijuí, 2000.

5. Rodrigues, S. P. J.; Atas do II Congresso Internacional - Educação, Ambiente e Desenvolvimento, Leiria, Portugal, 2016.

6. Sá, E. F.; Quadros, A. L.; Mortimer, E. F.; Silva, P. S.; Talim, S. L.; Revista Brasileira de Educação 2017, 22, 625.

7. Borralho, A.; Fialho, I. Em Ensino Superior: inovação e qualidade na docência; Leite, C., Zabalza, M., eds.; CIIE - Centro de Investigação e Intervenção Educativas: Porto, 2012, p. 984.

8. Carvalho, A. M. P.; Sasseron, L. H.; Estudos Avançados 2018, 32, 43.

9. Schnetzler, R. P.; Quim. Nova 2002, 25,14.

10. Cianeto: a sombra por trás da mineração do ouro, disponível em https:// www.ecycle.com.br/cianeto/, acessada em janeiro 2022.

11. Torres, A.; Suplementos minerais quelados: o que significa? disponível em https://andreiatorres.com/blog/2017/metal-quelado, acessada em janeiro 2022.

12. Scott, P.; Mortimer, E. F.; Ametller, J.; Studies in Science Education 2011, 47,3 .

13. Vigotski, L. S.; A construção do pensamento e da linguagem, $2^{\mathrm{a}}$ ed., Ed. WMF Martins Fontes: São Paulo, 2009.

14. Damasio, A.; Descartes' error: Emotion, reason and the human brain, Avon Books: New York, 1994.

15. Simpson, R. D.; Koballa, T. R.; Oliver, J. S.; Crawley, F. E. Em Handbook of research on science teaching and learning; Gabel, D. L., ed.; Macmillan: New York, 1994, p. 211.

16. DeNight, S. (1992). Writing to Learn Activities in Writing across the Curriculum Classrooms, ERIC Digest, 1992 (ED360646).

17. Klein, P.; Educational Psychology Review 1999, 11, 203.

18. Chatel, R. G.; Writing to Learn in Science. A Curriculum Guide. Coventry Science Center, Eric Center, 1997 (ED414196).

19. Reynolds, J. A.; Thaiss, C.; Katkin, W.; Thompson, R. J.; CBE - Life Sciences Education 2012, 11, 17.

20. Knipper, K. J.; Duggan, T. J.; The Reading Teacher 2006, 59, 462.

21. Pelger, S.; Nilsson, P.; Res Sci Educ 2016, 46, 439.

22. Wenzel, J. S.; Maldaner, O. A.; Quim. Nova 2014, 37, 908.

23. Sotério, C.; Queiroz, S. L.; Quim. Nova 2020, 43, 1163.

24. Oliveira, J. R. S.; Queiroz, S. L.; Quim. Nova 2014, 37, 1559.

25. Assis Brasil, L. A.; Letras de Hoje 2015, 50, 105.

26. Toma, H. E.; Ferreira, A. M. C.; Serra, O. A.; Quim. Nova 2002, 25, 66.

27. Nakagaki, S.; Ucoskia, G. M.; Rebouças, J. S.; Ferreira, A. M. C.; Quim. Nova 2017, 40, 680 .

28. Silva, S. F.; Núñez, I. B.; Quim. Nova 2002, 25, 1197.

29. Kasseboehmer, A. C.; Ferreira, L. H.; Quim. Nova 2008, 31, 694.

30. Gomes, W. G. B.; Mendes, A. N. F.; Calefi, R. M.; Em $O$ ensino de química [recurso eletrônico]; Voigt, C. L. eds.; Ponta Grossa (PR): Atena Editora, 2019, cap. 9.
31. Carriazo, J. G.; Quim. Nova 2011, 34, 1085.

32. Leite, A. C. B.; Leite, M. A. B.; Enseñanza de las Ciencias 2013, 31, 253.

33. Simões Neto, J. E.; Campos, A. F.; Marcelino-Jr., C. A. C.; Avances en Ciencias e Ingeniería 2013, 4, 61.

34. Silva, L. A.; Larentis, A. L.; Caldas, L. A.; Ribeiro, M. G. L.; Almeida, R. V.; Herbst, M. H.; Quim. Nova Esc. 2014, 36, 261.

35. Pougy, K. C.; Machado, S. P.; Quim. Nova 2020, 43, 127.

36. Kogikoski Jr., S.; Souza, J. S.; Homem-de-Melo, P.; Martinho, H.; Alves, W. A.; Ando, R. A.; Quim. Nova 2012, 35, 1264.

37. Silva, J. A. L.; Quim. Nova 2013, 36, 1458.

38. Orofino, H; Machado, S. P.; Faria, R. B.; Quim. Nova 2013, 36, 894.

39. Leal, B. C.; Luza, L.; Baibich, I. M.; Consorti, C. S.; Quim. Nova 2011, $34,1830$.

40. Baibich, I. M.; Butler, I. S.; Quim. Nova 2012, 35, 1474.

41. Macedo, A. N.; Almeida, M. R.; Quadros, A. L.; Quim. Nova 2021, 44, 659.

42. Klein, P.; International Journal of Science Education 2006, 28, 143.

43. McDermott M. A.; Hand B.; Em Using Multimodal Representations to Support Learning in the Science Classroom; Hand B.; McDermott M.; Prain V. eds. Springer, 2016. doi 10.1007/978-3-319-16450-2_10.

44. Atkins, P. W.; Shriver, D. F.; Overton, T. L.; Rourke, J. P.; Weller, M. T.; Armstrong, F. A.; Química Inorgânica, 4. ed., Porto Alegre: Bookman, 2008.

45. Peron, K. A.; Sotério, C.; Queiroz, S. L.; Educación Química 2021, 32, 74.

46. Kress, G.; Multimodality: A social semiotic approach to contemporary communication. EUA/Canadá: Routledge, 2009.

47. Kress, G.; Before Writing: Rethinking the Paths to Literacy, Routledge: Londres 1997.

48. Gualberto, C. L.; Pimenta, S. M. de O.; Diálogo das Letras, 2016, 05, 31.

49. Prain V.; Hand B.; Em Using Multimodal Representations to Support Learning in the Science Classroom; Hand, B., McDermott, M., Prain, V., eds.; Springer: New York, 2016, cap. 1.

50. Miller, M. E.; Hamann, M.; Kroon, F. J.; PLoS One 2020, 15, e0240792.

51. Nicol, M. A.; Fleming, C. A.; Paul, R. L.; Em The Extractive Metallurgy of Gold in South Africa; Stanley, G. G., ed.; Johannesburg, The South African Institute of Mining and Metallurgy, 2001, disponível em https:// www.saimm.co.za/Conferences/ExtractiveMetallurgyOfGold/0831Chapter15.pdf, acessada em janeiro 2022.

52. Ciminelli, V. S. T.; Gomes, A. D.; Em Extração de Ouro: Princípios, Tecnologia e Meio Ambiente; Trindade, R. B. E., Barbosa Filho, O., eds.; 2002, disponível em http://mineralis.cetem.gov.br/handle/cetem/1220, acessada em janeiro 2022.

53. Prado, M. R.; Revista ensino superior 2013, 11, 16.

54. Silva, E. M.; Reinaldo, M. A. G. M.; Ilha Desterro 2016, 69, 141. 